Empirical Validation of Multi-Zone HVAC System Model: Evaluation of Existing Infiltration Models used in Building Energy Simulation

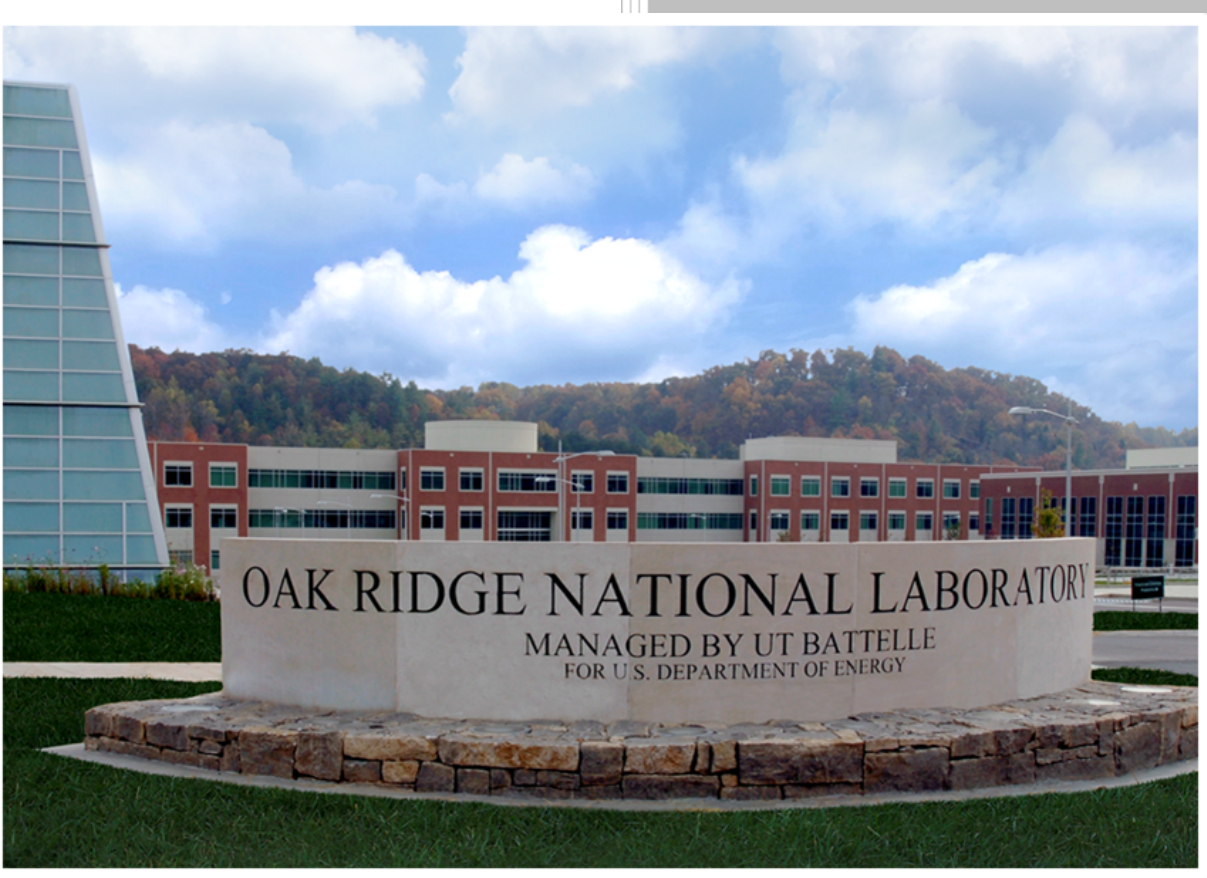

Approved for public release.

Distribution is unlimited.

Piljae Im, Ph.D.

Yeonjin Bae, Ph.D.

Seungjae Lee, Ph.D. Joshua New, Ph.D.

Date: June 30, 2020 


\section{DOCUMENT AVAILABILITY}

Reports produced after January 1, 1996, are generally available free via US Department of Energy (DOE) SciTech Connect.

Website www.osti.gov

Reports produced before January 1, 1996, may be purchased by members of the public from the following source:

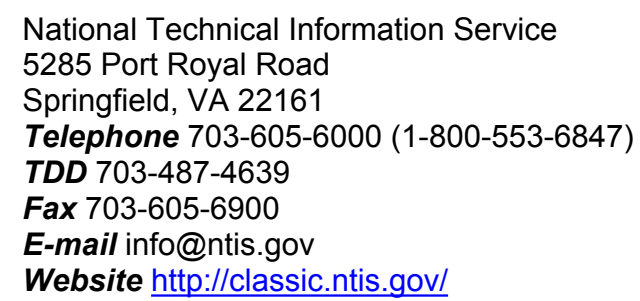

Reports are available to DOE employees, DOE contractors, Energy Technology Data Exchange representatives, and International Nuclear Information System representatives from the following source:

Office of Scientific and Technical Information

PO Box 62

Oak Ridge, TN 37831

Telephone 865-576-8401

Fax 865-576-5728

E-mail reports@osti.gov

Website http://www.osti.gov/contact.html

This report was prepared as an account of work sponsored by an agency of the United States Government. Neither the United States Government nor any agency thereof, nor any of their employees, makes any warranty, express or implied, or assumes any legal liability or responsibility for the accuracy, completeness, or usefulness of any information, apparatus, product, or process disclosed, or represents that its use would not infringe privately owned rights. Reference herein to any specific commercial product, process, or service by trade name, trademark, manufacturer, or otherwise, does not necessarily constitute or imply its endorsement, recommendation, or favoring by the United States Government or any agency thereof. The views and opinions of authors expressed herein do not necessarily state or reflect those of the United States Government or any agency thereof. 
Energy and Transportation Science Division

\title{
Empirical Validation of Multi-Zone HVAC System Model: Evaluation of Existing Infiltration Models used in Building Energy Simulation
}

\author{
Piljae Im \\ Yeonjin Bae \\ Seungjae Lee \\ Joshua New
}

Date Published: June 30, 2020

\author{
Prepared by \\ OAK RIDGE NATIONAL LABORATORY \\ Oak Ridge, TN 37831-6283 \\ managed by \\ UT-BATTELLE, LLC \\ for the \\ US DEPARTMENT OF ENERGY \\ under contract DE-AC05-00OR22725
}




\section{TABLE OF CONTENTS}

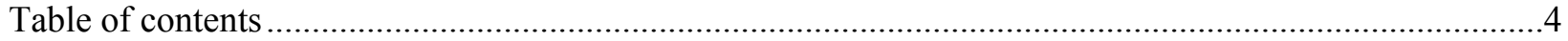

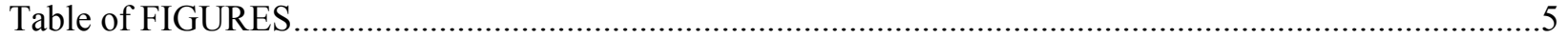

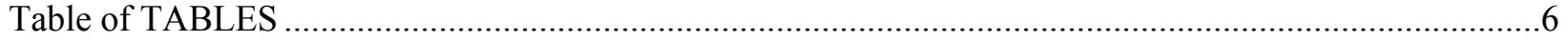

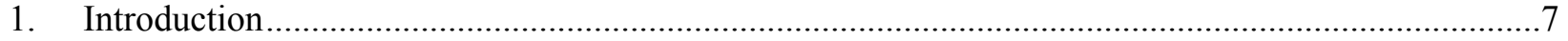

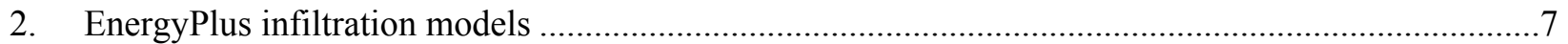

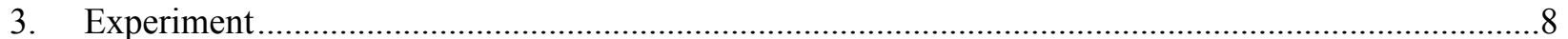

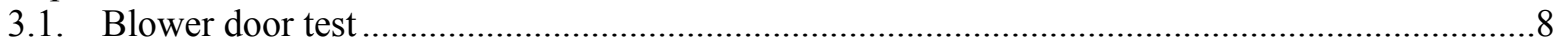

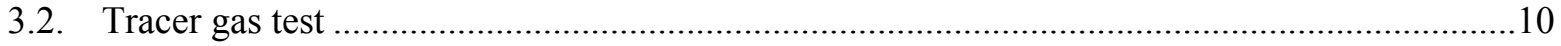

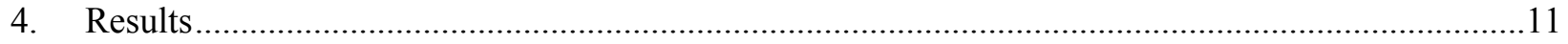

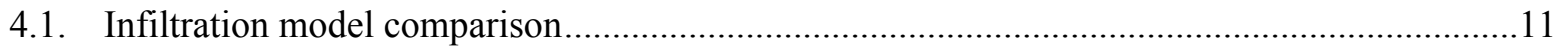

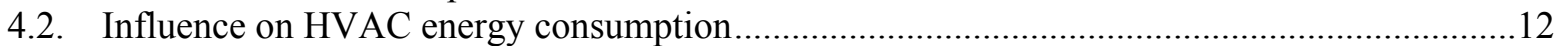

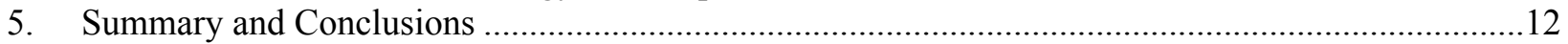

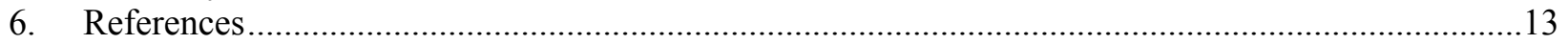




\section{TABLE OF FIGURES}

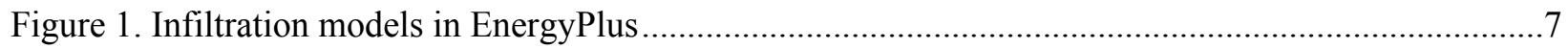

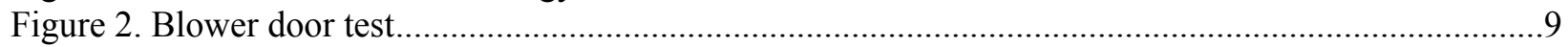

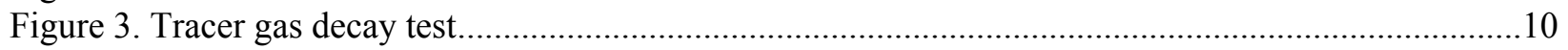

Figure 4. (a) Estimated and predicted infiltration rates (timeseries); (b) scattered plot showing the relationship between the estimated infiltration rate versus wind speed and indoor/outdoor absolute temperature difference.

Figure 5. Hourly reheat energy consumption with different infiltration models using (a) measured building envelope airtightness of the FPR and (b) assuming it was 2.95 times leakier. 


\section{TABLE OF TABLES}

No table of figures entries found. 


\section{Introduction}

Infiltration can have a significant impact on building loads. Studies have shown that infiltration can account for $15-40 \%$ of annual space conditioning needs in commercial buildings (Emmerich et al. 2019; Younes et al. 2012). The driving force of infiltration is the pressure difference across the building envelope caused by wind, the stack effect (known as buoyancy effect), and the operation of ventilation equipment. Wind pressure is governed by wind direction, speed, building shape, and other structures around the building. The stack effect is a function of the building height and air density differences of ambient air (Han, 2015). The effect of wind is dominant in low-rise residential buildings, and the stack effect is dominant in highrise buildings (ASHRAE 2017).

In building energy simulation programs (e.g., EnergyPlus), various empirical infiltration models (e.g., the effective leakage area model, the flow coefficient model) are available to simulate infiltration rates. To help users in selecting a proper infiltration model for modeling of the two-story Flexible Research Platform (FRP), the team evaluates the existing infiltration models in EnergyPlus based on field measurements from the FRP. The blower door and tracer gas decay tests were performed in the FRP. The blower door test result was used to estimate input parameters required in the infiltration models. The actual infiltration rates were estimated with the tracer gas decay test results.

\section{EnergyPlus infiltration models}

In EnergyPlus, three infiltration modeling options are available in the following objects: (1) ZoneInfiltration: DesignFlowRate, (2) ZoneInfiltration: EffectiveLeakageArea, and (3) ZoneInfiltration: FlowCoefficient. Four different sets of coefficients are tested using the ZoneInfiltration: DesignFlowRate object so that a total of six models are used for this study. It should be noted that these coefficients do not account physically or empirically for depressurization effects due to HVAC or exhaust fan operation. Figure 1 shows these six different infiltration models and their required input parameters. The blower door test result (typically reported as volumetric airflow rate $\left(\mathrm{m}^{3} / \mathrm{h}\right)$ at $75 \mathrm{~Pa}$ for commercial buildings) needs to be converted to a design infiltration rate $\left(\mathrm{m}^{3} / \mathrm{s}\right)$, an effective leakage area $\left(\mathrm{cm}^{2}\right)$, and a flow coefficient $\left(\mathrm{m}^{3} /\left(\mathrm{s} \cdot \mathrm{Pa}^{\mathrm{n}}\right)\right)$ before it is used in the appropriate infiltration model.

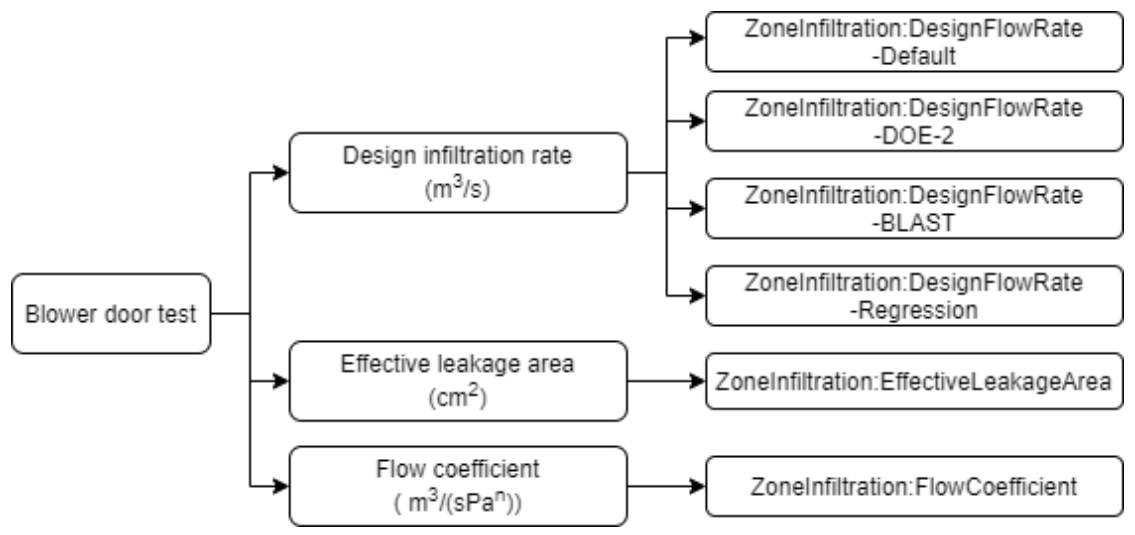

Figure 1. Infiltration models in EnergyPlus

The ZoneInfiltration: DesignFlowRate model uses the following empirical equation: 
Infiltration $=I_{\text {design }}\left(C_{0}+C_{1}|\Delta T|+C_{2} V+C_{3} V^{2}\right)$

where $I_{\text {design }}$ is the design infiltration rate, $C_{0}$ to $C_{3}$ are regression coefficients, $|\Delta T|$ is the absolute difference between indoor and outdoor dry-bulb temperatures, and $V$ is the wind speed. The default coefficients in EnergyPlus are $C_{0}=1, C_{1}=0, C_{2}=0$, and $C_{3}=0$ meaning that infiltration is a constant volumetric flow rate, and the wind and stack effects are not taken into consideration (EnergyPlus, 2018). The EnergyPlus predecessors, DOE-2 and BLAST have different set of coefficeints. The DOE-2 coefficients are $C_{0}=0, C_{1}=0, C_{2}=0$, and $C_{3}=0.224$, which consider only wind effects; the BLAST coefficients are $C_{0}$ $=0.606, C_{1}=0.03636, C_{2}=0.1177$, and $C_{3}=0$, which account for both wind and stack effects but are limited in the building types for which they are appropriate. Finally, a set of coefficients, derived from the tracer gas decay test results (refer to Section 3.2 for details), $C_{0}=0.13026, C_{1}=0.00110, C_{2}=0.01834$, and $C_{3}=$ 0.004200 , is used for the evaluation alongside the three sets of coefficients described above.

The ZoneInfiltration: EffectiveLeakageArea model uses a modified Sherman and Grimsrud model (ASHRAE 2017):

Infiltration $=\frac{A_{L}}{1000} \sqrt{C_{S}|\Delta T|+C_{w}(V)^{2}}$

where $A_{L}$ is the effective air leakage area at $4 \mathrm{~Pa}, C_{s}$ is the stack coefficient, and $C_{w}$ is the wind coefficient. The default values of $C_{s}$ are assigned based on building story and $C_{w}$ is determined based on building story and shelter class. For this study, $C_{s}$ is set to 0.000363 and $C_{w}$ is set to 0.000251 .

The ZoneInfiltration: FlowCoefficient model uses the following modified AIM-2 model:

Infiltration $=\sqrt{\left(c C_{s}|\Delta T|^{n}\right)^{2}+\left(c C_{w}(s * V)^{2 n}\right)^{2}}$

where $c$ is the flow coefficient, $s$ is the shelter factor coefficient, and $n$ is the pressure exponent. The default values of $C_{s}$ and $C_{w}$ are different from those used in the previous model and are determined based on building story, shelter factor, and the existence of a flue. $C_{s}, C_{w}, n$, and $s$ are set to $0.088,0.17,0.67$, and 0.7 in this study.

\section{Experiment}

The blower door and tracer gas decay tests were conducted at the two-story Flexible Research Platform (FRP), which is a slab-on-grade steel superstructure with a footprint of $13.4 \mathrm{~m} \times 13.4 \mathrm{~m}$ that is representative of light commercial buildings common to the existing US building stock. The FRP has ten conditioned zones and two unconditioned zones (e.g., staircase) with a $0.4 \mathrm{~m}$ thick exterior wall. It is unoccupied, but occupancy is emulated by process control of lighting, humidifiers for human-based latent loading, and heaters for miscellaneous electrical loads (MELs). The windows are evenly distributed, except on the east and north sides of the first floor, with a $28 \%$ window-to wall-ratio.

\subsection{Blower door test}

A blower door test was carried out to determine the building envelope airtightness (Figure 2). During this test, the heating, ventilating, and cooling (HVAC) system was off, and all interior doors were open. The airflow rates $\left(\mathrm{m}^{3} / \mathrm{s}\right)$ required to maintain differential pressures of 30 to $75 \mathrm{~Pa}$ in accordance with ASTM 
E779 (ASTM International, 2010) were determined. The building envelope airtightness $\left(I_{75 P}\right)$ was 0.9816 $\mathrm{m}^{3} / \mathrm{s}$ at $75 \mathrm{~Pa}(0.13 \mathrm{ACH}$ at $4 \mathrm{~Pa})$.

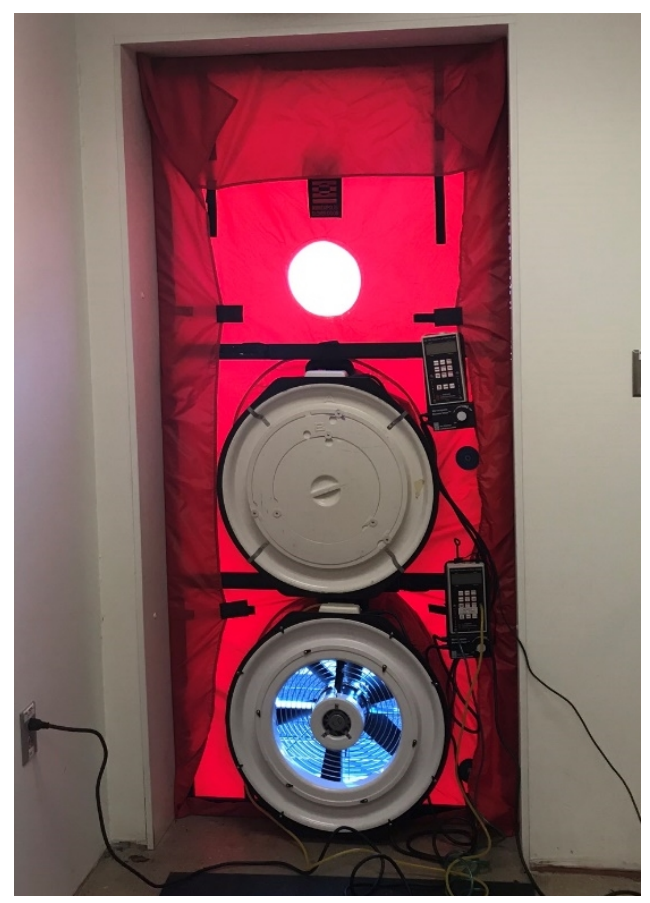

Figure 2. Blower door test

For the ZoneInfiltration: DesignFlowRate model, this $I_{75 P}$ value is converted to $I_{\text {design }}$ using Eqn. 4

$I_{\text {design }}=\left(\alpha_{\text {bldg }}+1\right) \cdot I_{75 P}\left(\frac{0.5 C_{s} \rho U_{H}^{2}}{75}\right)^{n}$

where the wind speed at building height $\left(U_{H}\right)$, the density of air $(\rho)$, the average surface pressure coefficients $\left(C_{s}\right)$, the urban terrain environment coefficient $\left(\alpha_{\mathrm{bldg}}\right)$, and the flow exponent $(n)$ are set to $4.47 \mathrm{~m} / \mathrm{s}, 1.18$ $\mathrm{kg} / \mathrm{m}^{3}, 0.1617,0.22$, and 0.65 , respectively (Gowri et al. 2009). The calculated $I_{\text {design }}$ for the FRP is 0.11 $\mathrm{m}^{3} / \mathrm{s}$.

For the ZoneInfiltration: EffectiveLeakageArea model, $I_{75 P}$ needs to be converted to effective leakage area $\left(A_{L}\right)$ using Eqn. 5

$A_{L}=\sqrt{\frac{\rho}{2\left(\Delta p_{r, 1}\right)}} I_{75 P}\left(\frac{\Delta p_{r, 1}}{\Delta p_{r, 2}}\right)^{n}$

where $\Delta p_{r, 1}$ and $\Delta p_{r, 2}$ are two reference pressure differences. The calculated $A_{L}$ at $4 \mathrm{~Pa}$ for the FRP is 590 $\mathrm{cm}^{2}$.

For the ZoneInfiltration: FlowCoefficient model, $I_{75 P}$ needs to be converted to a flow coefficient $(c)$ shown in Eqn. 6

$c=\frac{I_{75 P}}{(\Delta p)^{n}}$ 
where $n$ is the pressure exponent (set to 0.65 ). The calculated $c$ for the FRP is $0.0617613 \mathrm{~m}^{3} /\left(\mathrm{s} \cdot \mathrm{Pa}^{\mathrm{n}}\right)$.

\subsection{Tracer gas test}

The tracer gas test was performed with a multichannel doser and sampler and a photoacoustic gas monitor (Figure 3). The tracer gas (R134a/tetrafluoroethane) is a nonflammable refrigerant. Six thermal zones were selected, and the tracer gas tests were carried out five times from March 2019 to June 2019.

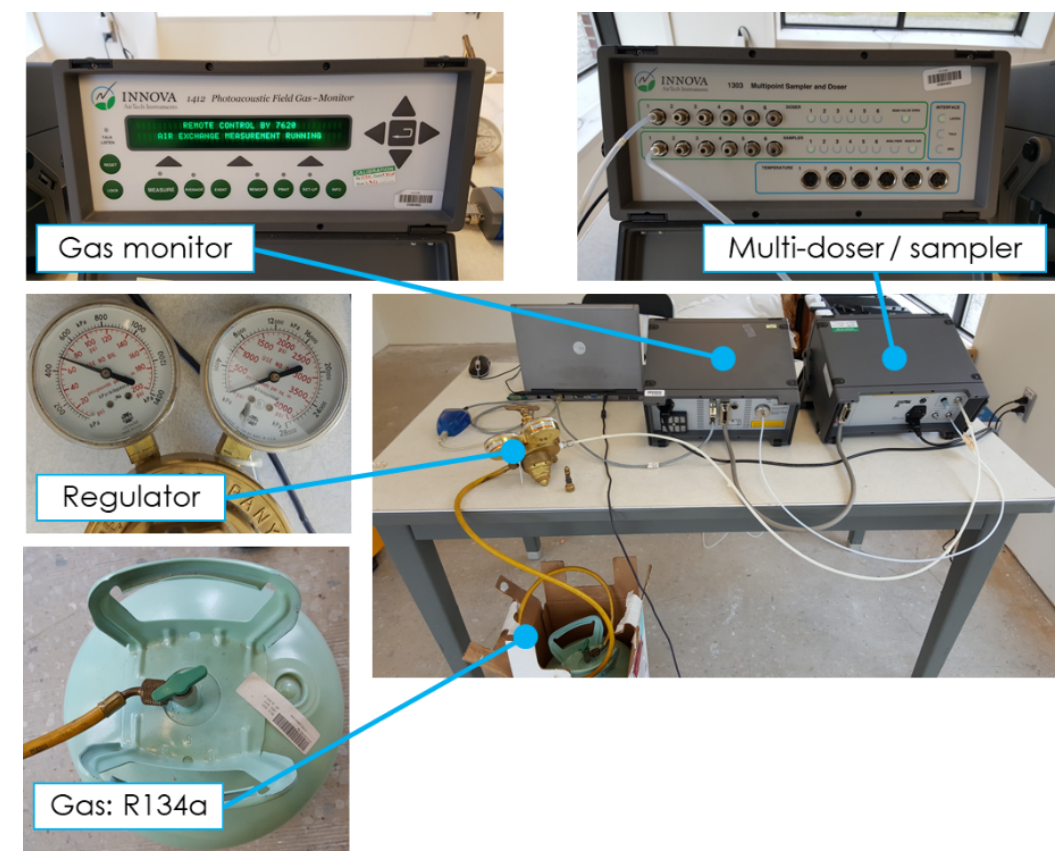

Figure 3. Tracer gas decay test

The tracer gas was injected into the return duct with HVAC system operation until the indoor concentration reached $600 \mathrm{mg} / \mathrm{m}^{3}$ in all measured locations ( $5 \mathrm{~min}$ to $6 \mathrm{~min}$ ). Assuming that the gas mixes thoroughly and instantaneously within the building, the average outdoor air change rate occurring between two measurements taken at times $t_{i}$ and $t_{i+1}$ was estimated using (Lagus and Persily, 1985):

$\bar{A}\left(t_{i}, t_{i+1}\right)=\frac{\left(\ln C\left(t_{i}\right)-\ln C\left(t_{i+1}\right)\right)}{t_{i+1}-t_{i}}$

where $\bar{A}\left(t_{i}, t_{i+1}\right)$ is the average air change rate $(1 / \mathrm{h})$, and $C\left(t_{i}\right)$ and $C\left(t_{i+1}\right)$ are the average concentrations $\left(\mathrm{mg} / \mathrm{m}^{3}\right)$ at times $t_{i}$ and $t_{i+1}(\mathrm{~h})$, respectively. The uncertainty in the estimation of the average air change rate was estimated using (ASTM International, 2006):

$S_{A\left(t_{i}, t_{i+1}\right)}^{2}=\frac{1}{\left(t_{i+1}-t_{i}\right)^{2} C\left(t_{i+1}\right)^{2}}+\frac{S_{C\left(t_{i}\right)}^{2}}{C\left(t_{i}\right)^{2}}$

where $S_{C\left(t_{i}\right)}^{2}$ and $S_{C\left(t_{i+1}\right)}^{2}$ are the variances of the measured concentrations at times $t_{i}$ and $t_{i+1}$, respectively. The $1^{\text {st }}$ quartile, median, and $3^{\text {rd }}$ quartile values of the estimated uncertainty over the tracer gas tests were 0.0196, 0.0321, and 0.0429, respectively. It should be noted that ASTM E741-11 recommends minimum durations between initial and final tracer measurements to determine an average air change rate that ranges from $4 \mathrm{~h}$ for a building that is relatively tight $(0.25 \mathrm{1} / \mathrm{h})$ and $15 \mathrm{~min}$ for a building that is not as tight $(4 \mathrm{l} / \mathrm{h})$. For simulation studies, an infiltration model for EnergyPlus was developed for the FRP with the estimated 
outdoor air change rate (or "infiltration rate") and the measured indoor-outdoor temperature difference and wind speed. Eqn. 1 was used as the model structure, and $\mathrm{C} 0$ to $\mathrm{C} 3$ were estimated for the FRP based on the test conditions: $0.13026,0.00110,0.01834$, and 0.004200 , respectively. It should be noted that these coefficients may not be applicable to other conditions, such as different weather or HVAC operation.

\section{Results}

\subsection{Infiltration model comparison}

The left graph in Figure 4 shows the measured hourly infiltration rate (red line) and the predicted values using the six infiltration models explained in Section 2. Accounting for HVAC operation, infiltration was reduced by $75 \%$ based on suggestions in the literature (Gowri et al. 2009) but has not be validated with data.

By comparing the estimated infiltration rate and the testing conditions in Figure $4 \mathrm{~b}$, we can see that the infiltration rate is positively correlated with the wind speed (the Pearson correlation coefficient is 0.55). However, the correlation between the estimated infiltration rate and the temperature difference between indoor and outdoor is smaller (the Pearson correlation coefficient is -0.01). Based on this result, the stack effect is inferred to not be a significant driving factor in the infiltration rates of the test building. Thus, models overestimating the stack effect would be unsuitable for this building.

Except for the ZoneInfiltration: DesignFlowRate model that uses the regression coefficients, and which was trained using the measured data, the remaining models - especially "DOE-2," "EffectiveLeakageArea," and "FlowCoefficient" - show significantly high relative errors. For example, the median value of the predicted infiltration rates using the "DOE-2" model was only $15.4 \%$ of the median value of the measured rates (Figure 4). However, the absolute predictive error in the infiltration rate was small because the building is relatively airtight. If the airtightness of the target building is low (i.e., leaky) then the absolute predictive error would also increase. 


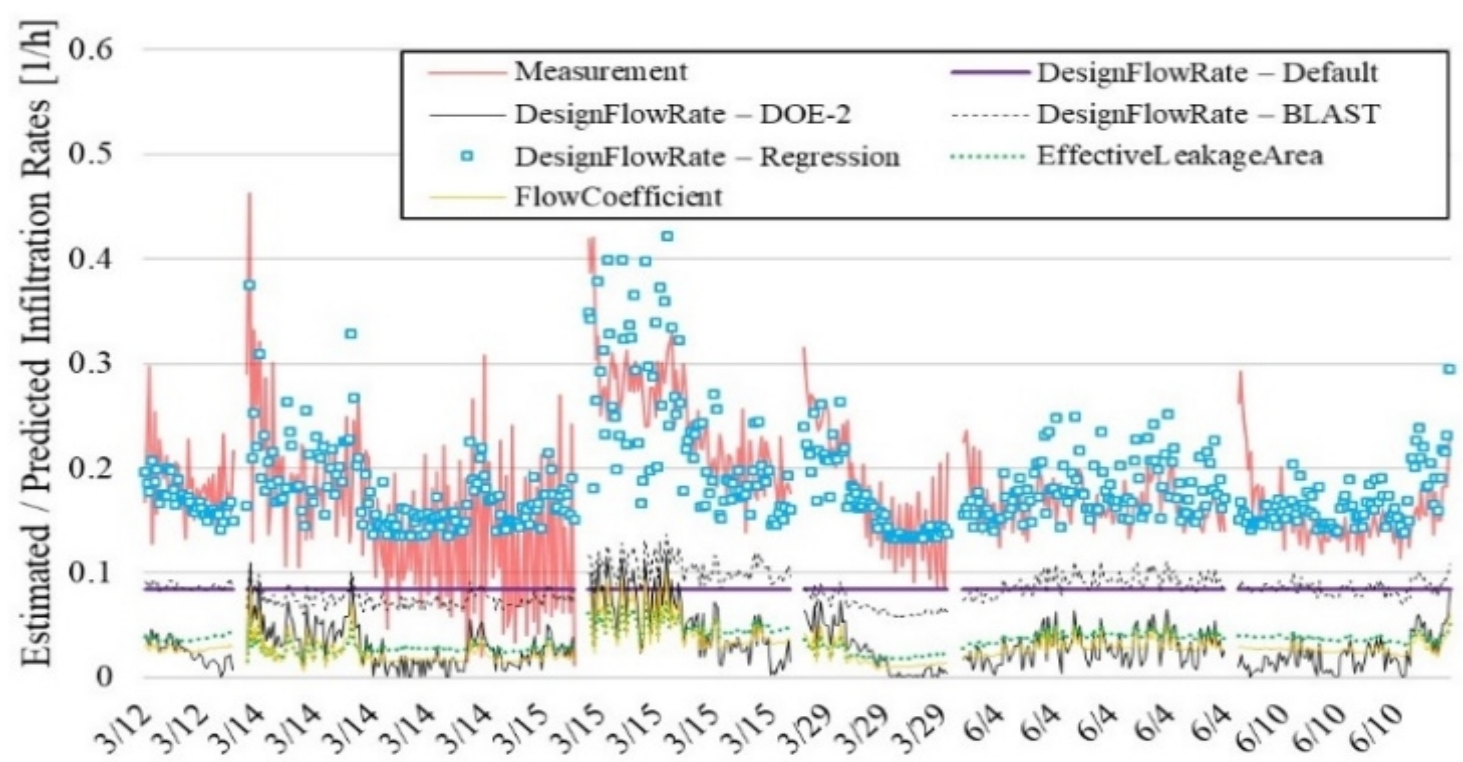

(a)

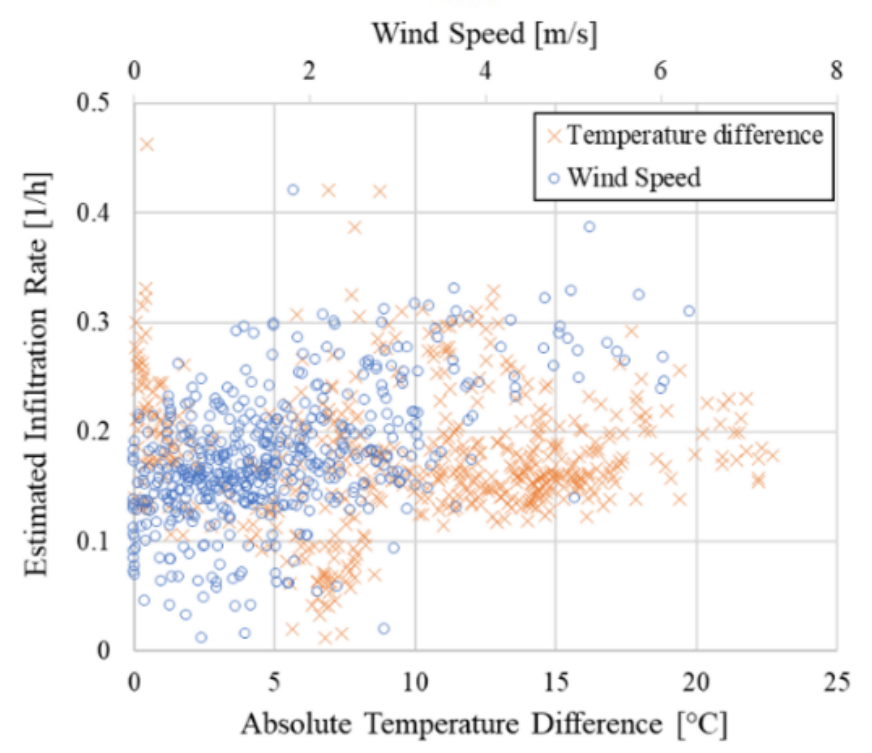

(b)

Figure 4. (a) Estimated and predicted infiltration rates (timeseries); (b) scattered plot showing the relationship between the estimated infiltration rate versus wind speed and indoor/outdoor absolute temperature difference

\subsection{Influence on HVAC energy consumption}

To investigate how the selection of the infiltration model influences the predicted building heating energy consumption, a simulation study was conducted with a validated EnergyPlus building model that reflects the thermal behavior of the test building (Im et at. 2020). 
The left graph in Figure 5 shows the hourly reheat energy consumption during the simulation period with the six different infiltration models. Differences between the model results look small. This is due to the small differences in the infiltration rates (Figure 4), i.e., because the building is airtight. Nevertheless, the total reheat energy consumption during the simulation period in the "Regression" case is $10.8 \%$ higher than that for the "DOE-2" case, which reveals that the energy impact of different infiltration models is not negligible even in a relatively airtight building. The right plot in Figure 5. illustrates the effect of the infiltration models when used for a leakier building. When using the default design infiltration rate from the DOE Commercial Prototypical Building Model (U.S.DOE, 2020), $0.4353 \mathrm{~m}^{3} / \mathrm{s}$ (i.e., 2.95 times leakier), the reheating energy use shows significant differences among the five non-constant infiltration models. For example, the total reheat energy consumption in the "BLAST" case is $30.4 \%$ higher than that in the "DOE2" case.
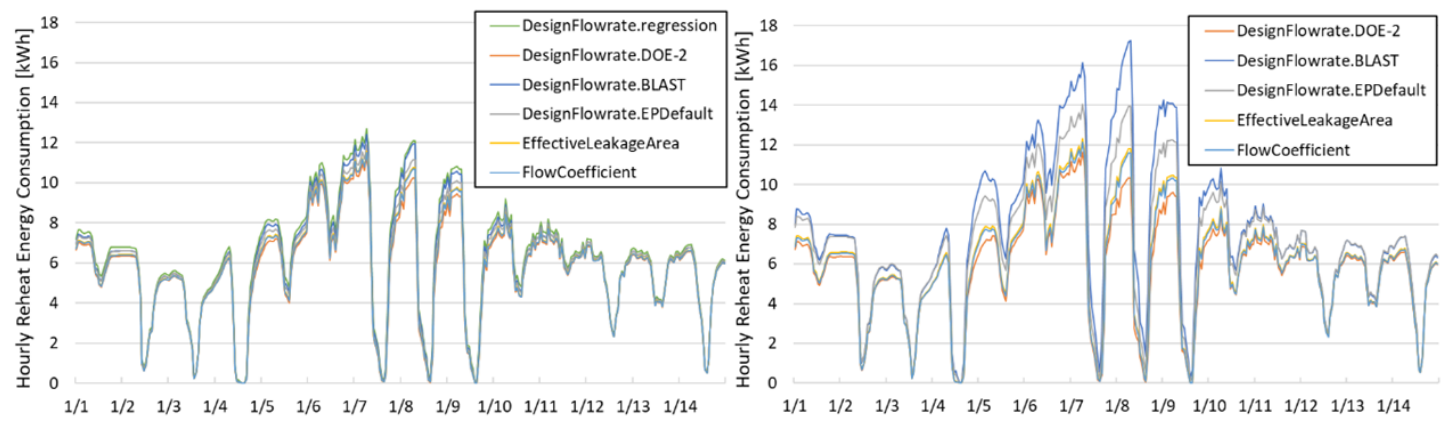

Figure 5. Hourly reheat energy consumption with different infiltration models using (a) measured building envelope airtightness of the FPR and (b) assuming it was 2.95 times leakier.

\section{Summary and Conclusions}

To provide the information required to select or use infiltration models for modeling of the FRP, the team conducted blower door and tracer gas decay tests in the FRP. The test results showed that (i) the airtightness of the FRP was high, and (ii) the stack effect is not a significant driving factor for the infiltration rate of the FRP. The following are the summary of the building airtightness and infiltration model coefficients estimated with the test results.

- Building envelope airtightness, $I_{75 P}$ :

$0.9816 \mathrm{~m}^{3} / \mathrm{s}$ at $75 \mathrm{~Pa}(0.13 \mathrm{ACH}$ at $4 \mathrm{~Pa})$

- Design infiltration rate, $I_{\text {design }}$ (Eqn. 1):

$0.11 \mathrm{~m}^{3} / \mathrm{s}$

- Effective air leakage area at $4 \mathrm{~Pa}, A_{L}$ (Eqn. 2): $590 \mathrm{~cm}^{2}$

- $\quad$ Flow coefficient, $c$ (Eqn. 3):

$0.0617613 \mathrm{~m}^{3} /\left(\mathrm{s} \cdot \mathrm{Pa}^{\mathrm{n}}\right)$

- DesignFlowRate (Eqn. 1) coefficients

estimated with tracer gas decay test results:

$0.13026,0.00110,0.01834,0.004200$

With the above test results, the team conducted a simulation study to investigate how the selection of the infiltration model influences the predicted building heating energy consumption. The simulation results showed that the effect of the infiltration model selection on the heating energy consumption was small because of the high airtightness of the FRP. The team will further investigate the infiltration pattern and its effects on the energy consumption of the FRP under different scenarios. 


\section{References}

ASHRAE. 2017. ASHRAE Handbook Fundamentals, American Society of Heating, Refrigerating, and AirConditioning Engineers.

ASTM International. 2006. ASTM International Standard E741-00. Standard Test Method for Determining Air Change in a Single Zone by Means of a Tracer Gas Dilution. West Conshohocken, PA: ASTM International.

ASTM. International. 2010. ASTM Standard E779. Standard Test Method for Determining Air Leakage Rate by Fan Pressurization. West Conshohocken, PA.

Emmerich S.J., McDowell T.P. and FAIA W.A. 2007. Simulation of the Impact of Commercial Building Envelope Airtightness on Building Energy Utilization/DISCUSSION. ASHRAE Transactions, 113, p.379.

Gowri K., Winiarski, D., and Jarnagin R. 2009. Infiltration modeling guidelines for commercial building energy analysis (No. PNNL-18898). Pacific Northwest National Lab (PNNL), Richland, WA.

Han G., Srebric J., and Enache-Pommer E. 2015. Different modeling strategies of infiltration rates for an office building to improve accuracy of building energy simulations. Energy and Buildings, 86: 288-95.

Im P., Joe J., Bae Y., New J. R. 2020. Empirical validation of building energy modeling for multi-zones commercial buildings in cooling season. Applied Energy, 261, 114374.

Lagus P., Persily P.D. 1985. A review of tracer-gas techniques. ASHRAE transactions.91(Part 11).

US Department of Energy. 2020. Commercial Prototype Building Models, Retrieved February 25, 2020, from https://www.energycodes.gov/development/commercial/prototype models.

US Department of Energy.2018. EnergyPlus Version 8.9 Documentation-Input output reference

Younes C., Shdid C. A., and Bitsuamlak G. 2012. Air infiltration through building envelopes: A review. Journal of Building Physics, 35(3): 267-302. 